\title{
Entomological Investigations on Malaria Vectors in Some War-Torn Areas in the Trincomalee District of Sri Lanka after Settlement of 30-Year Civil Disturbance
}

\author{
Nayana Gunathilaka, ${ }^{1,2}$ Menaka Hapugoda, ${ }^{1}$ \\ Wimaladharma Abeyewickreme, ${ }^{3}$ and Rajitha Wickremasinghe ${ }^{4}$ \\ ${ }^{1}$ Molecular Medicine Unit, Faculty of Medicine, University of Kelaniya, Ragama, Sri Lanka \\ ${ }^{2}$ Tropical Environmental Diseases \& Health Associates, No. 3 Elibank Road, Colombo 5, Sri Lanka \\ ${ }^{3}$ Department of Parasitology, Faculty of Medicine, University of Kelaniya, Ragama, Sri Lanka \\ ${ }^{4}$ Department of Public Health, Faculty of Medicine, University of Kelaniya, Ragama, Sri Lanka
}

Correspondence should be addressed to Nayana Gunathilaka; hasnayana@yahoo.com

Received 22 September 2014; Revised 19 January 2015; Accepted 19 January 2015

Academic Editor: Neena Valecha

Copyright ( 2015 Nayana Gunathilaka et al. This is an open access article distributed under the Creative Commons Attribution License, which permits unrestricted use, distribution, and reproduction in any medium, provided the original work is properly cited.

\begin{abstract}
Background. Malaria was an endemic problem in Trincomalee District, Eastern Province of Sri Lanka. Very few recent data concerning Anopheles are available which transmit malaria. Therefore, the aim of this study is to identify various Anopheles species and the dynamics of anophelines including malaria vectors in Trincomalee District for effective vector control under the current malaria elimination program embarked in the country. Method. Entomological surveys were conducted on a monthly basis, using five entomological techniques, namely, indoor hand collection (HC), window trap collection (WTC), cattle-baited net collection (CBNC), and cattle-baited hut collection (CBHC) from June 2010 to June 2012 in 32 study areas under five entomological sentinel sites. Results. Seventeen anopheline species were encountered, of which Anopheles subpictus was the predominant species in all sampling methods. It is noted that $A$. culicifacies and A. subpictus have adapted to breed in polluted water in urban settings which may cause serious implications on the epidemiology of malaria in the country. Conclusions. It is important to determine the abundance, biology, distribution, and relationship with climatic factors of main and secondary malaria vectors in Sri Lanka in order to initiate evidence based controlling programs under the current malaria elimination program in Sri Lanka.
\end{abstract}

\section{Background}

Malaria was endemic in the Dry Zone of Sri Lanka and was a major public health problem in the country in the past [1]. Chalmers reported the presence of 10 anopheline species in the country by Chalmers [2]. To date, 22 anopheline species have been reported in Sri Lanka [3]. Anopheles culicifacies was regarded as the only malaria vector in the country till about the early 1980s. Enzyme-linked immunosorbent assay (ELISA) based evidence has shown a large number of anopheline species to be infected with malaria parasites in addition to A. culicifacies. These include Anopheles aconitus, Anopheles annularis, Anopheles barbirostris, Anopheles nigerrimus, Anopheles pallidus, Anopheles subpictus, Anopheles tessellatus, Anopheles vagus, and Anopheles varuna. Among these species that have consistently been incriminated as malarial vectors are A. annularis, A. subpictus, A. varuna, and A. tessellatus [4]. Determination of risk of malaria transmission requires quick and accurate methods of identification of Anopheles mosquitoes, especially when targeting vector control [5].

Anopheles mosquitoes breed in areas with water bodies such as ponds, rivers, surface water, wells, and wastewaters [6]. Moreover, these areas are suitable for growth and development of various strains of mosquitoes as ponds, wells, and water bodies of different sizes that are available during rainy seasons [7].

Anopheles culicifacies, the primary vector of malaria in Sri Lanka, is known to breed primarily in stream and river systems. However, this species also breeds in other surface water collections and habitats in Sri Lanka [8]. Recent studies 
have reported that $A$. culicifacies breeds in brackish water bodies [9] and wastewater drains in the Trincomalee District of Sri Lanka [10, 11]. Mathematical models based on the correlation between the abundance of anopheline species and environmental factors such as rainfall, temperature, and humidity may be used to predict vector abundance and thereby malaria epidemics [12].

Over three decades of civil unrest, the conflict situation has had detrimental effects on vector control activities and management of malaria in Trincomalee District, which is an endemic region for malaria in Sri Lanka. With the background that only a few small-scale studies on malaria and its vectors have been reported from this district, a study was designed to explore the current abundance and distribution of malaria vectors in these areas.

Therefore, the aim of this study is to identify various Anopheles species and the dynamics of anophelines including malaria vectors in Trincomalee District for effective vector control under the current malaria elimination program embarked in the country.

\section{Methods}

2.1. Study Area. Trincomalee District is situated in the Dry Zone of the country within the Eastern Province of Sri Lanka. The district has a land area of $2,727 \mathrm{~km}^{2}$ and a population density of $135 / \mathrm{km}^{2}$. The average temperature varies from $24.8^{\circ} \mathrm{C}$ to $30.7^{\circ} \mathrm{C}$ and the district receives a mean annual rainfall of $1,649 \mathrm{~mm}$. The district has been traditionally endemic for malaria. However, very few entomological investigations have been carried out for about three decades in the Northern and Eastern Provinces until 2009, due to the terrorist war that took place in the country including this district.

Five sentinel sites, namely, Gomarankadawala, Ichchallampaththu, Mollipothana, Thoppur, and Padavisiripura, were selected for surveillance in consultation with the National Malaria Control Programme. The factors such as past malaria history, availability of breeding sites, an established agricultural community, and feasibility of field operations to collect relevant data were also considered in selecting the study areas.

The sentinel sites were over $20 \mathrm{Km}$ apart. In each sentinel site, 4 localities were selected within a $20 \mathrm{~km}$ radius of the sentinel site. Entomological surveillance was conducted in these 20 localities which lasted 1 week every month (Figure 1).

2.2. Mosquito Collection. Mosquitoes were collected at monthly intervals using five standard sampling methods from June 2010 to June 2012 according to WHO standard techniques for anopheline mosquitoes [13].

\subsection{Adult Anopheline Surveillance}

2.3.1. Indoor Hand Collection (HC). Hand collections were performed in randomly selected houses in each locality. Mosquitoes were collected a minimum of 180 houses per month in a sentinel site. Collections were made during the morning (06.00-08.30 hrs) by two vector collectors spending a maximum of ten minutes per house. Bedrooms, preferably with complete walls and the highest number of persons slept last night were given priority.

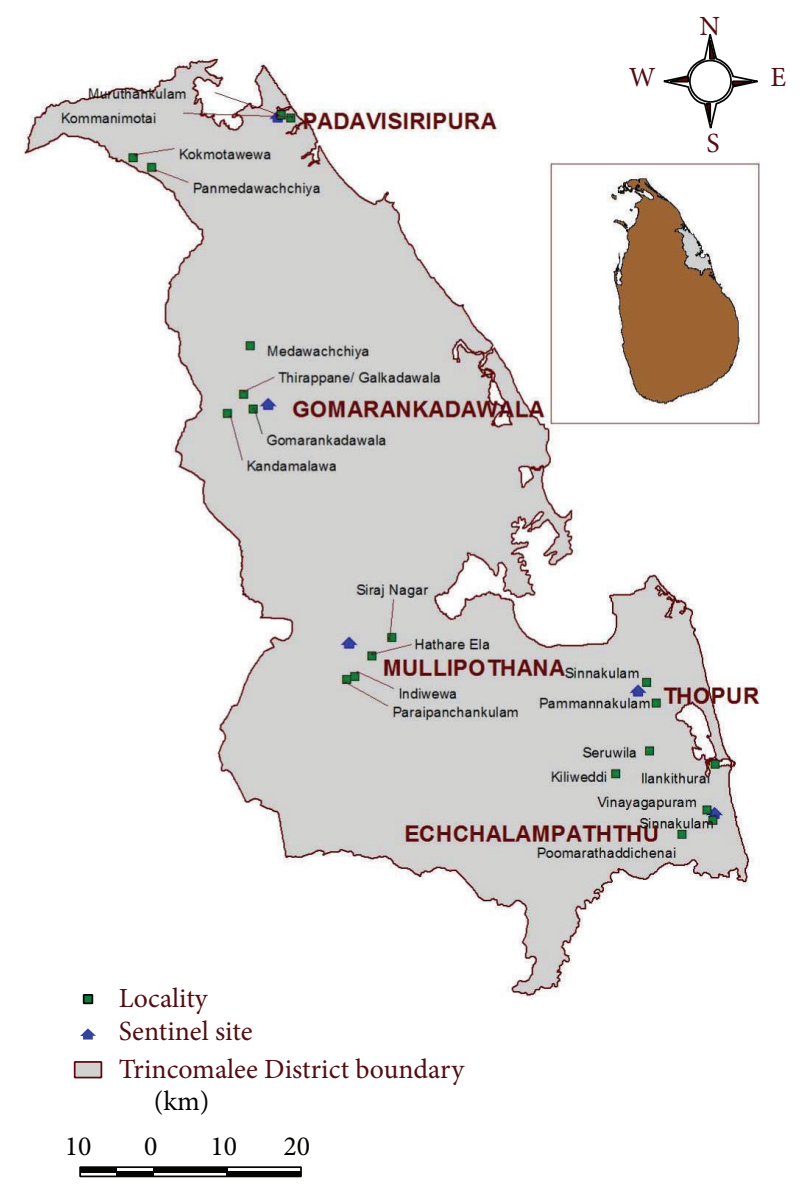

FIGURE 1: Map showing sentinel sites and localities in Trincomalee District.

2.3.2. Window Trap Collection (WTC). Two mosquito window (exit) traps were fixed in a sentinel site for 16 nights per month. On the following day mosquitoes were collected by two trained persons.

2.3.3. Cattle-Baited Net Trap Collection (CBNT). The trap was made out of white cotton drill $(3 \mathrm{~m} \times 3 \mathrm{~m} \times 1.5 \mathrm{~m})$ with net windows $(2 \mathrm{~m} \times 1 \mathrm{~m})$ on sides and erected using a strong centre pole of two-meter height and four side sticks of the same height. The trap was set about $50 \mathrm{~m}$ away from the houses and away from the place, where cattle are usually tethered or herded during the night. A distance of $15-25 \mathrm{~cm}$ gap was allowed between the lower edge of the net and the ground, enabling mosquitoes to enter. At sunset a cattle introduced into the trap in the evening and tethered to the pole fixed to the mid of the hut. The cattle removed at dawn for collecting the mosquitoes. All anophelines resting inside the trap were collected.

2.3.4. Cattle-Baited Hut Collection (CBHC). A standard hut was constructed in each locality. The size of the hut suited the size of the cattle bait and was approximately $2 \mathrm{~m} \times$ $1.25 \mathrm{~m} \times 1.25 \mathrm{~m}$. It was made of sticks, poles, and thatched with woven cadjan. At sunset, a calf was tethered to a strong pole inside the hut with no windows. A removable door made 
TABle 1: Anopheles collected from June 2010 to June 2012.

\begin{tabular}{lcccc}
\hline Sampling technique & Unit & Total number of units & Total number collected & Percentage (\%) \\
\hline LS & Dip & 598,046 & 21,347 & 24.34 \\
HC & Houses & 20,694 & 10,626 & 12.11 \\
WTC & Trap & 3,560 & 1,790 & 2.04 \\
CBHC & Trap & 1,620 & 11,622 & 13.25 \\
CBNC & Trap & 1,621 & 42,325 & 48.25 \\
\hline Total & & & 87,710 & 100 \\
\hline
\end{tabular}

out of sticks and cadjan was fitted to the hut to facilitate the movement of the calf and the collector in and out of the hut. A space of about 10-15 centimeters $(\mathrm{cm})$ between the ground and the cadjan thatched wall and about a five $\mathrm{cm}$ space between the roof and the wall were left for the movement of mosquitoes. All anophelines resting inside the hut were collected on the following day.

2.3.5. Anopheline Larval Surveillance (LS). All potential breeding habitats were identified in all 20 localities through a preliminary survey conducted for a period of one month prior to the research study and certain fixed and temporary breeding places were identified for the larval survey. A minimum of 50 dips were taken from each breeding habitat depending on the size of the breeding place using standard dippers ( $250 \mathrm{~mL}$ capacity). Large plastic pipettes and small white enamel pans were used for small and shallow water bodies. The Anopheles larvae were separated from the Culicine larvae. The Anopheles mosquito larvae were classified as early instar stage (I and II) or late instar stage (III and IV) according to Gillies and Coetzee [14].

2.4. Sample Identification. All mosquitoes collected by HC, WT, CBNT, and CBHT and adults emerging from larvae were identified using an achromatic magnifying lens $(\times 10)$ and the taxonomic keys [3].

2.5. Calculation of Mosquito Densities. The density of each mosquito species collected by CBHT, CBNT, and WTC was calculated as per trap densities (number of mosquitoes from each species/total number of traps) and $\mathrm{HC}$ as density per house (number of mosquito from each species/total number of houses surveyed), and larval densities were calculated as density per 100 dips \{ (number of mosquitoes from each species/total number of dips) $\times 100\}$.

2.6. Collection of Climatic Data. Monthly climatic data including rainfall $(\mathrm{RF})$, temperature (MT), and relative humidity (RH) of the Trincomalee District monitored at various locations were obtained from the Department of Meteorology, Colombo, Sri Lanka.

2.7. Data Analysis. The data obtained in the study were collected and analyzed with respect to Anopheles species abundance in the study area. These were interpreted in percentage and presented in tables. Pearson's correlation coefficients were used to determine the associations between climatic variables and anopheline densities.
2.8. Ethical Consideration. Ethical clearance to conduct the study was obtained from the Ethics Review Committee of the Faculty of Medicine, University of Kelaniya, Sri Lanka.

\section{Results}

3.1. Mosquito Collections. The overall results of the mosquito collection made by five mosquito sampling techniques named $\mathrm{CBHC}, \mathrm{CBNC}$, WTC, HC, and LS during the study period are given in Table 1. A total of 87,710 female mosquitoes representing 17 species were recorded throughout the study. The majority (62\%) of adults was collected by cattle-baited collections (CBHC and CBNC) in the district. Larval surveys recorded 24.3\% (21,347/87,710) of Anopheles from Trincomalee Districts. The density of each mosquito species collected by CBHT, CBNT, and WTC was calculated as per trap densities (number of mosquitoes from each species/total number of traps) and $\mathrm{HC}$ as density per house (number of mosquito from each species/total number of houses surveyed) and larval densities were calculated as density per 100 dips $\{$ (number of mosquitoes from each species/total number of dips) $\times 100\}$.

The most abundant species among the immature and adult collections was Anopheles subpictus (26\%). Anopheles culicifacies accounted for $1.3 \%$ of both adult and larval collections. The distribution of mosquitoes collected from different techniques is given in Table 2. The density of A. culicifacies, A. subpictus, and all anophelines by different surveillance technique is illustrated in Table 3.

\subsection{Entomological Monitoring}

3.2.1. Indoor Hand Collection (HC). The density of indoor resting anophelines was monitored in selected houses in each locality. A total of 10,626 adults belonging to 13 anopheline species were collected. A. subpictus was the most predominant species, while A. culicifacies comprised only $0.01 \%$ $(2 / 10,626)$ of all indoor resting mosquitoes. All other anopheline species were present, but in much less densities $(<14 \%)$.

3.2.2. Window Trap Collection (WTC). A total of 1,790 Anopheles representing 12 species were recorded from 3,560 traps performed during the study period. A. subpictus (63.85\%) was the most abundant species $(1,143 / 1,790)$, followed by $12.12 \%(217 / 1,790)$ of Anopheles nigerrimus, $10.95 \%$ (196/1,790) of Anopheles vagus, 5.86\% (105/1,790) of Anopheles peditaeniatus, 3.52\% (63/1,790) of Anopheles barbirostris, $1.45 \%(26 / 1,790)$ of Anopheles pallidus, $0.84 \%$ (15/1,790) of 
TABLE 2: Relative abundance of anophelinesby sampling technique in the Trincomalee District.

\begin{tabular}{|c|c|c|c|c|c|}
\hline \multirow{2}{*}{ Anopheles species } & \multicolumn{5}{|c|}{ Number and percentage (\%) of mosquitoes collected by } \\
\hline & $\mathrm{CBHC}$ & CBNC & WTC & $\mathrm{HC}$ & LS \\
\hline A. aconitus & $5(0.04)$ & $17(0.04)$ & - & - & $53(0.25)$ \\
\hline A. aitkeni & $4(0.03)$ & - & - & - & - \\
\hline A. annularis & $600(5.16)$ & $1612(3.81)$ & $14(0.78)$ & $19(0.18)$ & $1038(4.86)$ \\
\hline A. barbirostris & $564(4.85)$ & $3976(9.39)$ & $63(3.52)$ & $203(1.91)$ & $1975(9.25)$ \\
\hline A. barbumbrosus & $17(0.15)$ & $311(0.73)$ & $5(0.28)$ & $13(0.12)$ & $278(1.3)$ \\
\hline A. culicifacies & $94(0.81)$ & $8(0.02)$ & $4(0.22)$ & $2(0.01)$ & $1068(5.0)$ \\
\hline A. jamesii & $138(1.19)$ & $764(1.81)$ & $1(0.06)$ & - & $79(0.37)$ \\
\hline A. karwari & - & $3(0.007)$ & - & - & - \\
\hline A. maculatus & $2(0.02)$ & - & - & - & $14(0.07)$ \\
\hline A. nigerrimus & $1774(15.26)$ & $12938(30.57)$ & $217(12.12)$ & $452(4.25)$ & $5267(24.67)$ \\
\hline A. pallidus & $521(4.48)$ & 808 (1.91) & $26(1.45)$ & $60(0.56)$ & $1430(6.69)$ \\
\hline A. peditaeniatus & 1209 (10.4) & $18185(42.97)$ & $105(5.86)$ & $212(1.99)$ & $3109(14.56)$ \\
\hline A. pseudojamesi & $71(0.61)$ & $430(1.02)$ & - & - & $81(0.38)$ \\
\hline A. subpictus & $5419(46.6)$ & $2104(4.97)$ & $1143(63.85)$ & 9158 (86.18) & $5278(24.72)$ \\
\hline A. tessellatus & $38(0.33)$ & $88(0.21)$ & $1(0.05)$ & $4(0.04)$ & $52(0.24)$ \\
\hline A. vagus & $1087(9.35)$ & $1052(2.48)$ & $195(10.95)$ & $473(4.45)$ & $980(4.59)$ \\
\hline A. varuna & $79(0.68)$ & $29(0.07)$ & $15(0.84)$ & $30(0.28)$ & $645(3.02)$ \\
\hline Total & $11622(100)$ & $42325(100)$ & $1790(100)$ & $10626(100)$ & $21347(100)$ \\
\hline
\end{tabular}

Anopheles varuna, 0.78\% (14/1,790) of Anopheles annularis, $0.28 \%$ (5/1,790) of Anopheles barbumbrosus, $0.22 \%$ (4/1,790) A. culicifacies, $0.05 \%$ (1/1,790) of Anopheles jamesii, and $0.05 \%$ (1/1,790) of Anopheles tessellatus.

3.2.3. Cattle-Baited Net Collection (CBNC). A total of 42,325 anophelines belonging to 15 species were recorded from 1,621 hut days. The average number of mosquitoes collected per day is 26.11 . A peditaeniatus, $42.97 \%(18,185 / 42,325)$, was the most dominant species followed by $A$. nigerrimus, $30.57 \%$ $(12,938 / 42,325)$.

3.2.4. Cattle-Baited Hut Collection (CBHC). A total of 11,622 anophelines representing 16 species were collected from 1,620 trap-days of collection. The average number of anopheline collected per trap day was 7.2. Among the 16 species collected, the most predominant species was A. subpictus, $46.62 \%(5,419 / 11,622)$, followed by $15.26 \%(1,774 / 11,622)$ of A. nigerrimus, $10.4 \%(1,209 / 11,622)$ of $A$. peditaeniatus, $9.35 \%$ $(1,087 / 11,622)$ of $A$. vagus, $5.16 \%(600 / 11,622)$ of $A$. annularis, $4.85 \%(564 / 11,622)$ of $A$. barbirostris, $4.48 \%(521 / 11,622)$ of $A$. pallidus, and $1.91 \%(138 / 11,622)$ of $A$. jamesii.

3.2.5. Larval Surveillance (LS). Immature stages were collected from all types of breeding sites recorded in each locality of the sentinel sites on a monthly basis (Table 3 ). A total of 21,347 anophelines were recorded representing 15 species from 598,046 dips. A. subpictus $24.72 \%(5,278 / 21,347)$ was predominant followed by $24.67 \%(5,267 / 21,347)$ of $A$. nigerrimus and $14.56 \%(3,109 / 21,347)$ of $A$. peditaeniatus. Some species were limited only to selective breeding habitats (Table 4).

3.3. Climate Data. The total annual rainfall in 2010 and 2011 was $1376.22 \mathrm{~mm}$ and $2532.44 \mathrm{~mm}$, respectively. The highest rainfall was recorded during the months of October to December (Figure 2). The mean relative humidity was $60 \%$ during the study period while the mean monthly temperature ranged from $25.0^{\circ} \mathrm{C}$ to $30.4^{\circ} \mathrm{C}$ (Figure 2).

3.4. Correlations between Anopheline Densities and Climatic Data. The association between both adult and larval anopheline densities and climatic variables, namely, RF, TM, and RH, were investigated by correlation analysis.

3.4.1. Indoor Hand Collection (HC). A. culicifacies density in $\mathrm{HC}$ was positively, though not significantly, correlated with RF having a one-month lag period $(r=0.25 ; P=0.23)$ and a two-month lag period ( $r=0.39 ; P=0.063)$. A. subpictus and all anopheline densities in HC were positively, though not significantly, correlated with RF having one-month lag $(r=$ $0.05 ; P=0.81, r=0.087 ; P=0.69$, resp.).

A. culicifacies, A. subpictus, and all Anopheles densities recorded from $\mathrm{HC}$ were positively, though not significantly, correlated with $\mathrm{RH}$ having a one-month lag period ( $r=0.28$; $P=0.15, r=0.21 ; P=0.35, r=0.24 ; P=0.27$, resp.) and a two-month lag period $(r=0.35 ; P=0.11, r=0.30 ; P=0.17$, $r=0.32 ; P=0.14$, resp.). Mean temperature of the current month was positively correlated with $A$. subpictus density in $\mathrm{HC}(r=0.28 ; P=0.177)$ (Table 5).

3.4.2. Window Trap Collection (WTC). A. culicifacies and A. subpictus densities were positively, but not significantly, correlated with RF of the current month $(r=0.36,0.29$; $P=0.07,0.15$, resp.). There was a positive but not significant correlation between $\mathrm{RH}$ of the current month, $A$. culicifacies $(r=0.242 ; P=0.245)$. A. subpictus density was positively correlated with $\mathrm{RH}$ having a one-month lag period ( $r=0.399 ; P=0.054)$ and a two-month lag period 


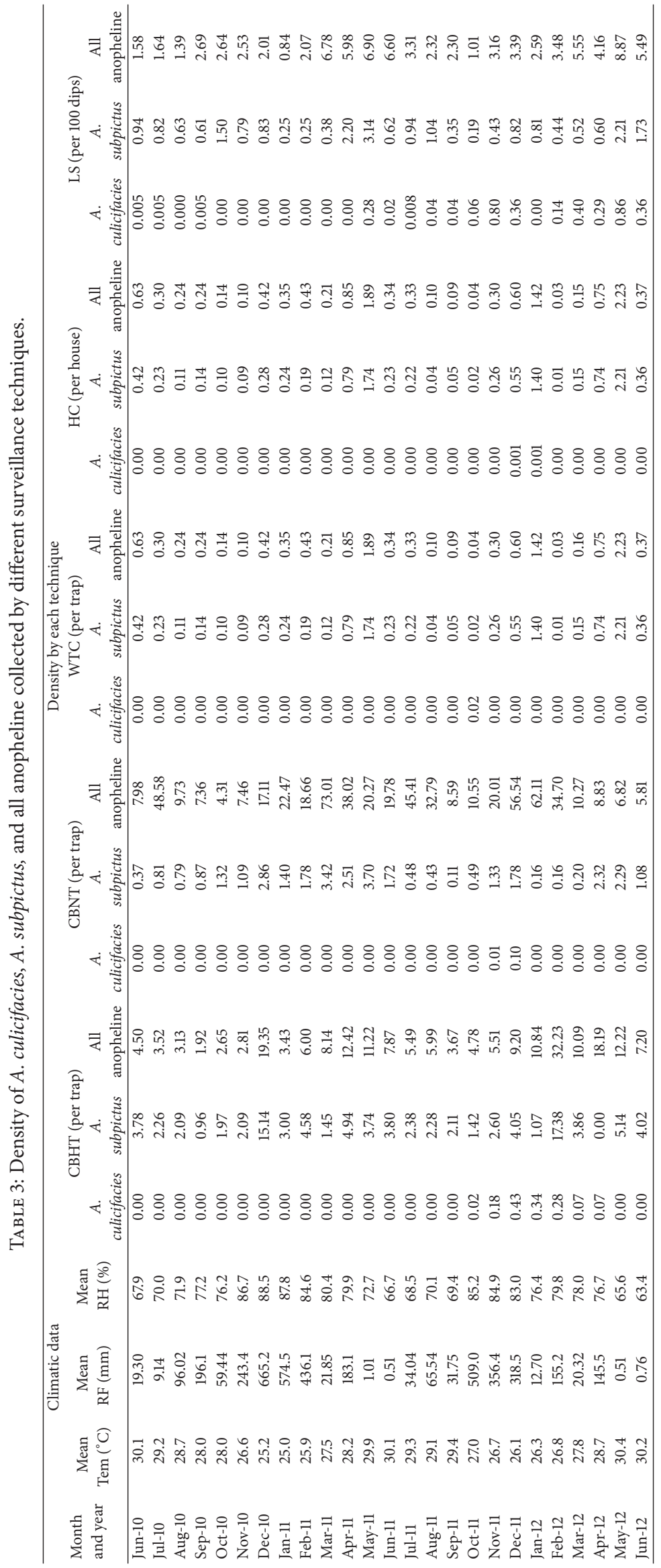




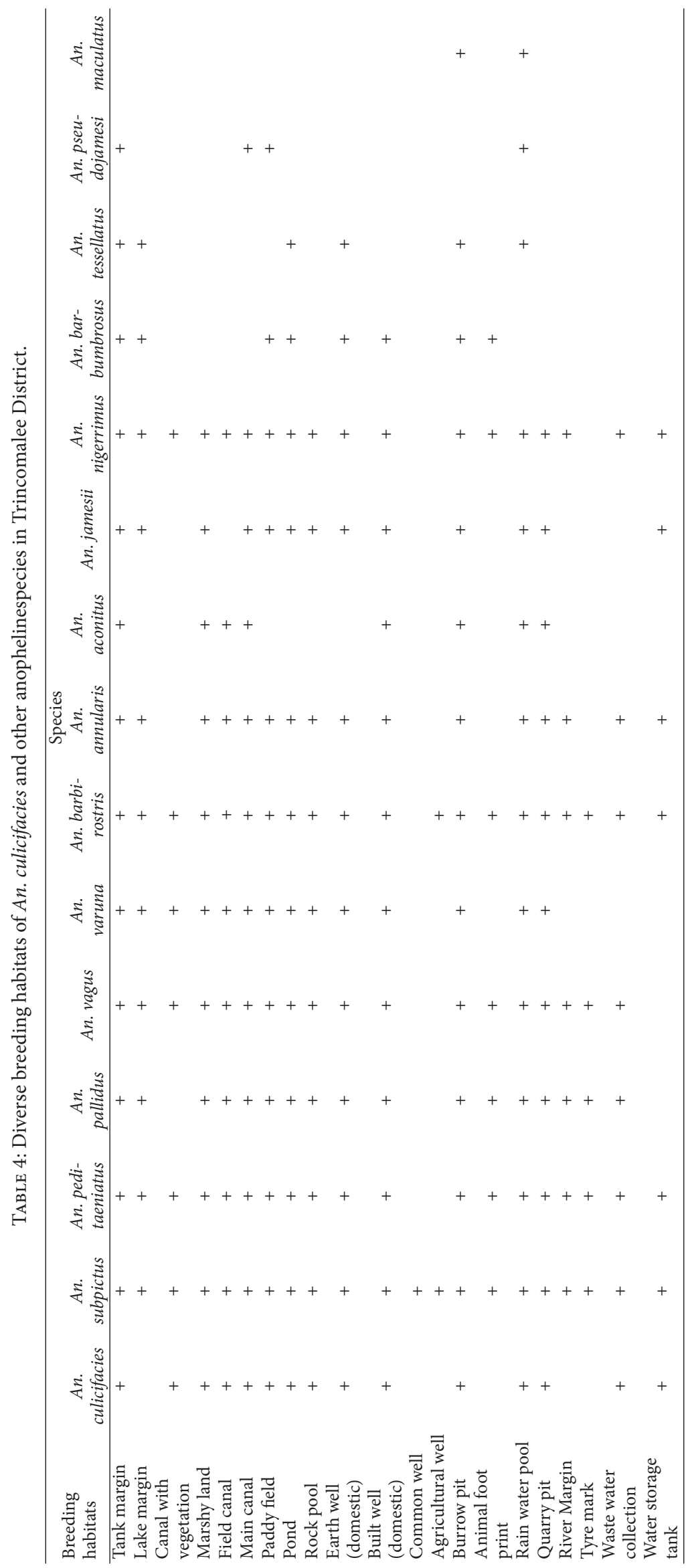




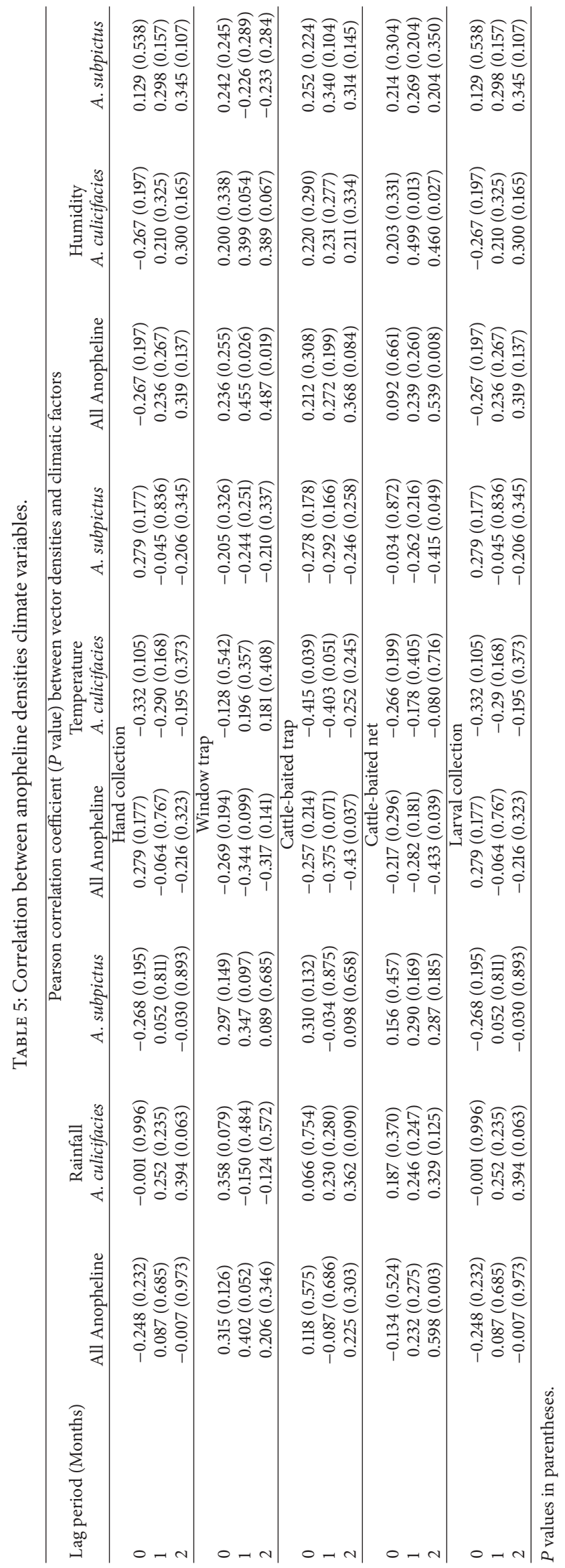




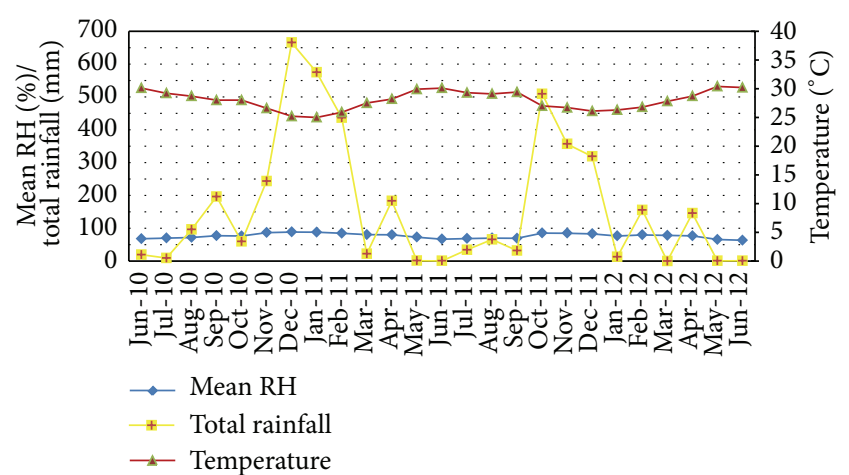

Figure 2: Climatic details of the Trincomalee District during the study period.

$(r=0.389 ; P=0.067)$. A. culicifacies density was positively correlated (not significant though) with TM having a onemonth $(r=0.196 ; P=0.357)$ and a two-month lag periods $(r=0.18 ; P=0.408)$ (Table 5).

3.4.3. Cattle-Baited Net Collection (CBNC). A. culicifacies density was positively correlated with RF of the current month $(r=0.187 ; P=0.37)$, having one-month lag $(r=0.25$; $P=0.25)$ and two-month lag periods $(r=0.33 ; P=0.125)$. The RH of the current month $(r=0.21 ; P=0.3)$, having one-month lag period $(r=0.27 ; P=0.20)$ and having twomonth lag period ( $r=0.2 ; P=0.35)$, was correlated with $A$. culicifacies. Mean temperature of the current month, having one- and two-month lag periods, was negatively correlated with $A$. culicifacies and A. subpictus densities (Table 5). None of these correlations were statistically significant.

3.4.4. Cattle-Baited Hut Collection (CBHC). A. culicifacies density was positively correlated, though not significant, with $\mathrm{RF}$ of the current month $(r=0.066 ; P=0.75)$, having one-month lag $(r=0.23 ; P=0.28)$ and two-month lag periods $(r=0.36 ; P=0.09)$. A. subpictus was positively correlated with the RF of the current month $(r=0.31 ; P=$ $0.31)$ and RF having two-month lag period ( $r=0.31 ; P=$ 0.13 ). Relative humidity of the current month, having oneand two-month lag periods, was positively correlated with $A$. culicifacies and A. subpictus densities (Table 5). None of these correlations were statistically significant. All anophelines densities including $A$. culicifacies and A. subpictus densities were negatively correlated, though not significant, with TM of the current month, having one- and two-month lag periods.

3.4.5. Larval Surveillance (LS). In larval collections, A. culicifacies, A. subpictus, and all Anopheles were positively correlated with the TM of the current month $(r=0.18 ; P=0.39$, $r=0.53 ; P=0.007, r=0.30 ; P=0.14$, resp.), having a onemonth lag period with $A$. culicifacies $(r=0.004 ; P=0.97)$ and $A$. subpictus ( $r=0.30 ; P=0.15)$. Larval density of $A$. subpictus was also positively correlated with RH having a twomonth lag period $(r=0.14 ; P=0.95)$. There was a significant negative significant correlation between TM of the current month, having two-month lag periods, with A. supictus and

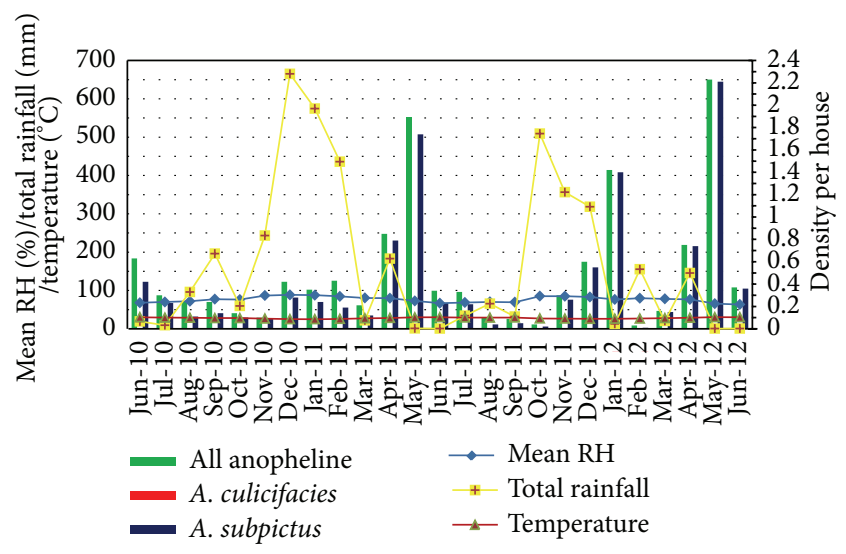

Figure 3: Density of A. culicifacies, A. subpictus, and all anophelines collected by $\mathrm{HC}$ with climatic variables.

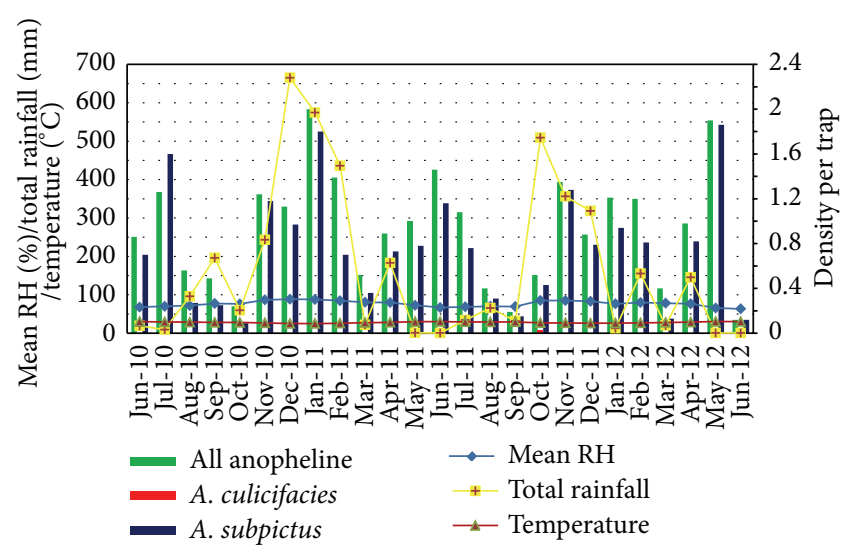

Figure 4: Density of A. culicifacies, A. subpictus, and all anophelines collected by WTC with climatic variables.

all anophelines (Table 5). None of these correlations were statistically significant.

\subsection{Seasonal Variation of Anophelines}

3.5.1. Indoor Hand Collection (HC). The density of all anopheline was observed to be high during the monsoonal rains (May to July and November to January) (Figure 3). A. subpictus was the most abundant and only indoor resting species collected throughout the study period. A. culicifacies was also collected from Trincomalee District only in December 2011 and January 2012, but very little in numbers when compared to A. subpictus.

3.5.2. Window Trap Collection (WTC). All anopheline density by WTC was high during November to January periods (Figure 4). This is due to the occurrence of monsoonal rains in these seasons. The highest indoor resting densities by WTC peaked approximately one to two months after a high rainfall received for a particular period. The similar pattern was observed for A. subpictus also A. culicifacies was detected only in October 2011. 


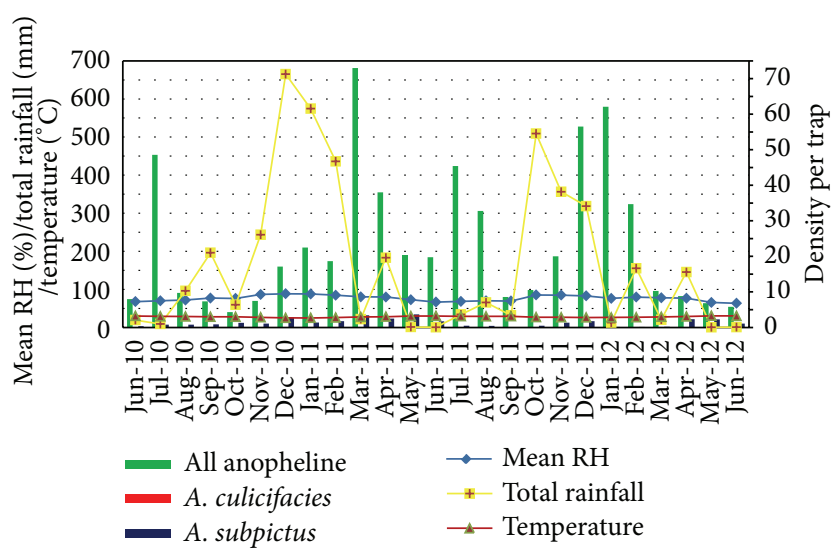

Figure 5: Density of A. culicifacies, A. subpictus, and all anophelines collected by $\mathrm{CBNC}$ with climatic variables.

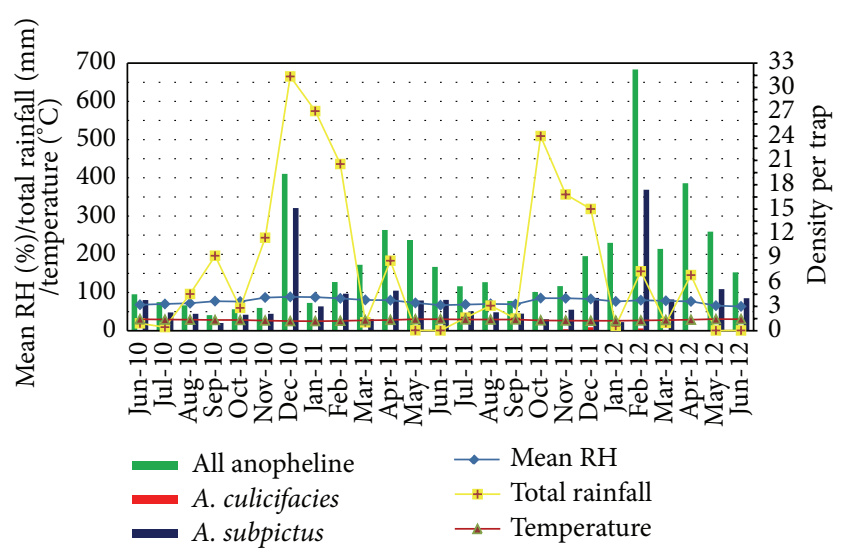

FIgUre 6: Density of A. culicifacies, A. subpictus, and all anophelines collected by $\mathrm{CBHC}$ with climatic variables.

3.5.3. Cattle-Baited Net Collection (CBNC). The highest densities were observed during May to June and November to February (Figure 5). All anopheline density was high in July 2010, March 2011, and January 2012. A. subpictus density was observed to be high during December 2010 to May 2011 with increasing rainfall. A. culicifacies was found only during November and December 2011. The highest density was observed in December 2011.

3.5.4. Cattle-Baited Hut Collection (CBHC). The outdoor resting anopheline density by $\mathrm{CBHC}$ peaked approximately one to two months after that of the indoor resting population. The highest A. subpictus density was observed in February 2012 (Figure 6). A. subpictus density by CBHC was low, when the indoor resting by $\mathrm{HC}$ was observed to be high. $A$. culicifacies was found to be fewer in numbers. It was recorded only from October 2011 to April 2012 throughout the study period, where the highest density was detected in December 2011.

3.5.5. Larval Surveillance (LS). The larval density of all anophelines was high during February to May in both 2011 and 2012, approximately one to three months after heavy

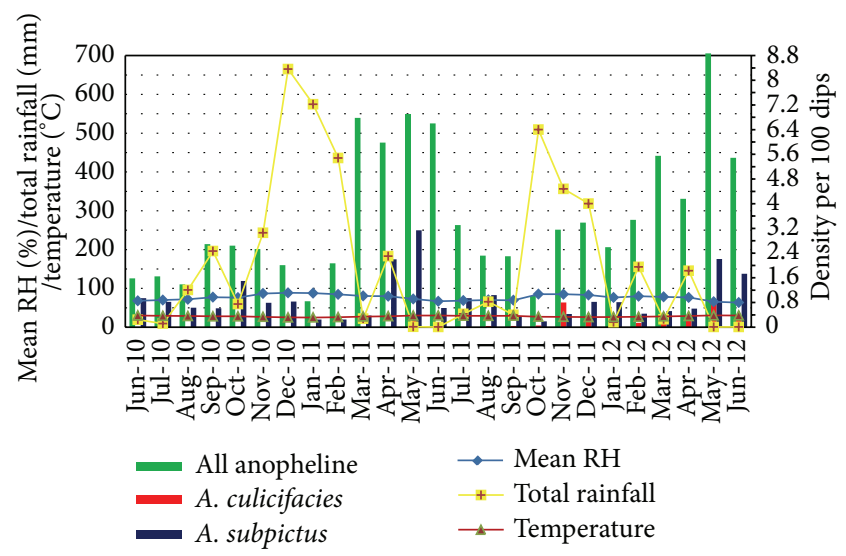

Figure 7: Density of A. culicifacies, A. subpictus, and all anophelines collected by LS with climatic variables.

rains were received in December 2010 and October 2011, respectively (Figure 7). A similar pattern was not identified for A. subpictus densities, where the higher densities were found in March to May in both years. A. culicifacies was detected continuously since May 2011 to June 2012 except in January 2012. The highest density was detected in June 2012.

\section{Discussion}

The abundance of malaria vector Anopheles mosquitoes has not been studied in some parts of Sri Lanka, especially in Northern and Eastern Provinces over the past 30 years because of the security situations. Mosquito species may have shifted their niche with changing weather patterns and ecology in order to attain a wide dissemination in the environment.

The current investigation was focused on the study of malaria vectors and their abundance in selected areas in Trincomalee District. A total of 17 anopheline species were recorded in the study areas. Vector incrimination studies done for most of these anopheline species under experimental laboratory and field conditions have been reported to play a role in malaria transmission in Sri Lanka [15]. Hence, the study of their abundance becomes important for implementation of effective malaria control measures.

Anopheles subpictus, the predominant species in all collection techniques we carried out including intradomestic habitats, was the only anopheline species recorded throughout the study period in indoor habitats. Although A. subpictus has been incriminated only as a secondary vector of malaria in Sri Lanka [16], given its relative abundance in intra- and peridomestic habitats, it is possible that it plays a more dominant role as a primary vector in the transmission of malaria in Sri Lanka.

The outdoor resting anopheline population demonstrated two distinctive peaks corresponding to periods following monsoonal rains. About $47 \%$ and $5 \%$ of collections from CBHT and CBNT, respectively, were A. subpictus. In cattlebaited net trap collections, Anopheles peditaeniatus (43\%) and Anopheles nigerrimus (31\%) were observed; they were 
not encountered among the indoor resting populations, indicating their exclusive exophilic nature. The presence of A. nigerrimus in these areas might contribute to malaria transmission since this species is considered as a secondary vector for malaria. However, indoor residual spraying of insecticides (IRS) is commonly used as the major malaria control intervention targeting adult mosquitoes. Therefore, the tendency of resting adult vector mosquitoes in outdoor resting surfaces will depreciate the effectiveness of IRS as a controlling measure. Hence, the health authorities need to be vigilant to prevent any future epidemics of malaria in these areas.

Cattle-baited trap collections captured all anopheline species prevalent in a particular area. This technique may be good to study the general mosquito abundance in an area especially in monitoring vector species during a malaria elimination phase as in Sri Lanka and even thereafter. The results revel that the mosquitoes collected from CBNT were approximately five times than those of CBHT. The possible reason for this observation may be the fact that since the $\mathrm{CBHT}$ is a fixed one at a permanent place, the collection may vary with the seasonality. However, the CBNT is a mobile trap; therefore, during the study period the net traps were placed in different locations proximity to breeding sites and resting places of adult mosquitoes.

The seasonal distribution of anopheline varies in time and space depending upon environmental conditions and availability of breeding habitats. Climatic factors are the most accepted microecological factors that affect mosquito populations. These include temperature, precipitation, and relative humidity [17]. Climate predicts, to a large extent, the natural distribution of malaria [18].

The minimal larval breeding in the district was observed, when rainfall was above $400 \mathrm{~mm}$ a month probably due to flushing of larvae as a result of high levels and rapid flow of water in streams and rivers and subsequent flooding that may have led to larval deaths due to reduction in oxygen tension causing physical harm to the larvae [19].

Larvae of Anopheles mosquitoes have been found in aquatic bodies such as rice fields, the edges of streams and rivers, and small temporary rain pools. Many species prefer habitats with vegetation, while some breed in open, sunlit pools. The frequency of larval occurrence varied considerably in different habitats. In this study, all anopheline species were reported breeding in tank margins. Anopheles subpictus was the predominant species indicating the presence in all 21 habitat categories. There was no habitat found to have larvae of a single anopheline species. Some species such as Anopheles annularis, Anopheles varuna, Anopheles tessellatus, Anopheles barbirostris, Anopheles barbumbrosus, Anopheles pallidus, and Anopheles pseudojamesi were limited to selective breeding habitats. This pattern of larval distribution has been attributed to the specificity of mosquito species to prefer different degrees of physicochemical properties of larval habitats [20].

Interestingly, Anopheles culicifacies, A. subpictus, and some potential vectors were encountered in a variety of breeding habitats including blocked drains with wastewater having low dissolved oxygen levels $(<3 \mathrm{mg} / \mathrm{L})$. This has serious implications on the epidemiology of malaria in general and the application of control measures in the country in particular, which have focused on rural populations based on the bioecology of the vector. Rapid unplanned urbanization observed in many parts of the country is changing the context of human population settlements and natural ecosystem interactions that may have contributed to adaptation of anopheline breeding sites that we observed in this study.

The evidence of the adaptation and survival of $A$. culicifacies and A. subpictus in polluted water should be a warning signal of the potential for the emergence of urban malaria in Sri Lanka, a phenomenon that has not been reported yet. This needs to be seriously considered by malaria control authorities as the majority of malaria cases reported recently in the country are imported cases detected in people in urban areas. Moreover, adaptation of anophelines to breed in polluted water in urban areas could be a serious concern when $A$. stephensi plays an important role in transmitting urban malaria in neighboring Southern India.

During this study, there was minimal variation in temperature and humidity. The mean monthly temperature ranged between $25.0^{\circ} \mathrm{C}$ and $30.4^{\circ} \mathrm{C}$; the upper limit of $\mathrm{RH}$ was over $62 \%(62.2 \%-88.5 \%)$. The minimal variation in temperature and humidity may also have contributed to the lack of relationship between the abundance of anopheline species and climate variables.

The fact that this study could not sample all possible resting or breeding sites of anophelines in the different localities is acknowledged; our assessment of overall anopheline abundance is based on obtaining representative samples from the selected sampling sites. Mosquito collections were done at monthly intervals. It is possible that rapid changes in weather conditions and availability of breeding sites within the month may have influenced our results. The association between rainfall and density of vectors may have been confounded by changes in the environment affecting the mosquito population and application and effectiveness of malaria control interventions in these areas.

Only a few mosquito species recorded in the country have been incriminated as malarial vectors. It is important to monitor the density of these species, both indoors and outdoors, as well as their breeding habitats for application of vector control measures as Sri Lanka is on the threshold of malaria elimination.

A key point from these results is the potential impact of other mosquito species mainly A. subpictus and A. nigerrimus on malaria transmission. This survey makes an important contribution in assessing relative abundances of mosquito vectors which may not be considered in malaria control intervention and may point to ways in which mosquito control could be targeted to address the transmission potential of these vectors. Additionally, A. culicifacies may actually contribute a relatively small amount of transmission given its low abundance, which again is an important point for effective vector control under the current malaria elimination program in Sri Lanka. 


\section{Conclusions}

Routine surveys for mosquito should be an ongoing function of every mosquito controlling program. It is important to determine the abundance, distribution, biology, and relationship with climatic factors of main and secondary malaria vectors in Sri Lanka in order to apply efficient controlling programs under the current malaria elimination program in Sri Lanka.

\section{Conflict of Interests}

The authors have no conflict of interests concerning the work reported in this paper.

\section{Authors' Contribution}

Nayana Gunathilaka was responsible for sample collection, identification of field samples, and writing the paper; Menaka Hapugoda performed identification of field samples; Rajitha Wickremasinghe performed identification of field samples and data analysis; Wimaladharma Abeyewickreme was responsible for supervision of the surveillance programme and reviewing the paper. All authors read and approved the final paper.

\section{Acknowledgments}

The authors would like to thank Dr. Panduka Wijeyarathne, the Program Director of the Malaria Elimination Program of Tropical and Environmental Diseases and Health Associates (TEDHA) Pvt. Ltd., for his encouraging support and financial assistance from the Global Fund for Aids, Tuberculosis, and Malaria (GFATM) (Round 8) through TEDHA (Grant no. SRL809G11M). The authors would also thank entomological field staff of the TEDHA Malaria Elimination Program in the Trincomalee District for their help in collecting samples.

\section{References}

[1] K. T. Silva, "Malaria eradication as a legacy of colonial discourse: the case of Sri Lanka," Parassitologia, vol. 36, no. 1-2, pp. 149-163, 1994.

[2] A. J. Chalmers, Anophelinae found in Ceylon, vol. 2 of Spolia Zeylanica, 1905.

[3] F. P. Amerasinghe, "A guide to the identification of anopheline mosquitoes (Diptera; Culicidae) of Sri Lanka.1 Adult females," Ceylon Journal of Science (Biological Sciences), vol. 2, pp. 13-29, 1990.

[4] P. H. Amerasinghe, F. P. Amerasinghe, F. Konradsen, K. T. Fonseka, and R. A. Wirtz, "Malaria vectors in a traditional dry zone village in Sri Lanka," The American Journal of Tropical Medicine and Hygiene, vol. 60, no. 3, pp. 421-429, 1999.

[5] M. A. Appawu, K. M. Bosompem, S. Dadzie et al., "Detection of malaria sporozoites by standard ELISA and VecTest dipstick assay in field-collected anopheline mosquitoes from a malaria endemic site in Ghana," Tropical Medicine and International Health, vol. 8, no. 11, pp. 1012-1017, 2003.

[6] M. W. Service, A Guide to Medical Entomology, Macmillain International College Edition, Oxford University Press, 1980.
[7] U. A. Ahmed, "Morphological identification of malaria vectors within Anopheles species in parts of Kano State, Nigeria," Bayero Journal of Pure and Applied Sciences, vol. 4, no. 2, pp. 160-163, 2011.

[8] T. A. Abhayawardana, "Breeding preference of Anopheles culicifacies in Galketiyagama area in Kurunegala district," in Proceedings of the Annual Session of the Sri Lanka Association of Advancement of Sciences, pp. 53-54, Colombo, Sri Lanka, November 1995

[9] P. A. D. H. N. Gunathilaka, M. A. S. T. Fernando, M. D. Hapugoda, P. Wijeyerathne, A. R. Wickramasinghe, and W. Abeyewickreme, "Some observations on abundance and breeding habitats of Anopheles sp. in Trincomalee, Sri Lanka," in Proceedings of the 66th Annual Session of the Sri Lanka Association of Advancement of Sciences, p. 2, Colombo, Sri Lanka, 2010.

[10] P. A. D. H. N. Gunathilaka, M. A. S. T. Fernando, M. D. Hapugoda, P. Wijeyerathne, A. R. Wickramasinghe, and W. Abeyewickreme, "Breeding of Anopheles culicifacies in different water bodies in the District of Sri Lanka," in Proceedings of the 13th Annual Research Symposium, pp. 56-57, University of Kelaniya, Colombo, Sri Lanka, 2012.

[11] N. Gunathilaka, T. Fernando, M. Hapugoda, R. Wickremasinghe, P. Wijeyerathne, and W. Abeyewickreme, "Anopheles culicifacies breeding in polluted water bodies in Trincomalee District of Sri Lanka," Malaria Journal, vol. 12, no. 1, article 285, 2013.

[12] D. A. R. Premasiri, A. R. Wickremasinghe, D. S. Premasiri, and N. Karunaweera, "Malarial vectors in an irrigated rice cultivation area in southern Sri Lanka," Transactions of the Royal Society of Tropical Medicine and Hygiene, vol. 99, no. 2, pp. 106-114, 2005.

[13] World Health Organization, Entomological Field Techniques for Malaria Control Part 1: Learner's Guide, World Health Organization, 1990.

[14] WHO, Manual on Practical Entomology in Malaria Part 2: Methods and Techniques, World health Organization, Geneva, Switzerland, 1975.

[15] F. Konradsen, F. P. Amerasinghe, W. Van der Hoek, and P. H. Amerasinghe, Malaria in Sri Lanka: Current Knowledge on Transmission and Control, International Water Management Institute, Colombo, Sri Lanka, 2000.

[16] P. H. Amerasinghe, F. P. Amerasinghe, R. A. Wirtz et al., "Malaria transmission by Anopheles subpictus (Diptera: Culicidae) in a new irrigation project in Sri Lanka," Journal of Medical Entomology, vol. 29, no. 4, pp. 577-581, 1992.

[17] E. Pampana, A Text Book of Malaria Eradication, Oxford University Press, London, UK, 1969.

[18] M. J. Bouma and H. J. Van Der Kaay, "The El Niño Southern Oscillation and the historic malaria epidemics on the Indian subcontinent and Sri Lanka: an early warning system for future epidemics?" Tropical Medicine and International Health, vol. 1, no. 1, pp. 86-96, 1996.

[19] G. R. A. Okogun, "Life-table analysis of Anopheles malaria vectors: generational mortality as tool in mosquito vector abundance and control studies," Journal of Vector Borne Diseases, vol. 42, no. 2, pp. 45-53, 2005.

[20] J. E. Gimmg, M. Ombok, L. Kamau, and W. A. Hawley, "Characteristics of larval anopheline (Diptera: Culicidae) habitats in western Kenya," Journal of Medical Entomology, vol. 38, no. 2, pp. 282-288, 2001. 


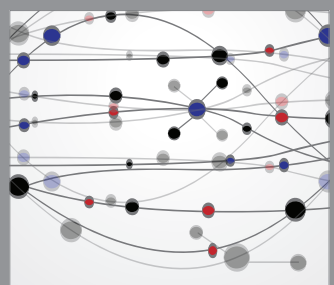

The Scientific World Journal
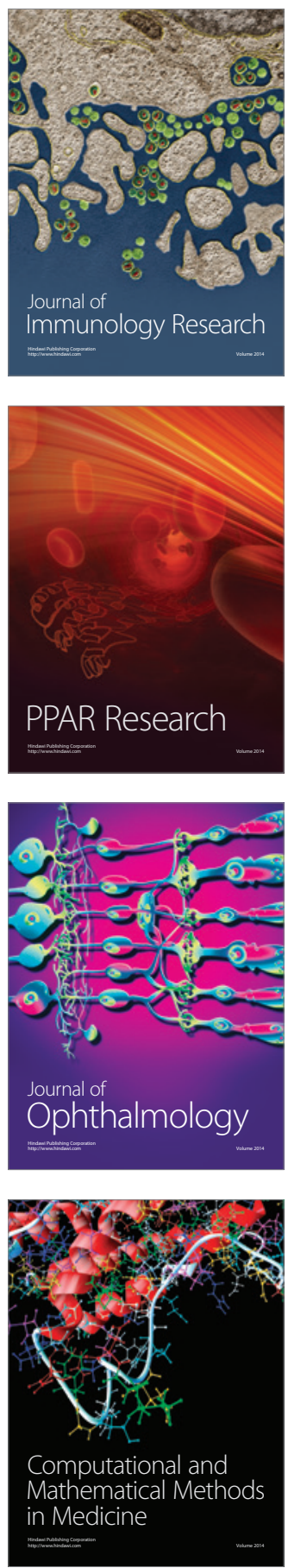

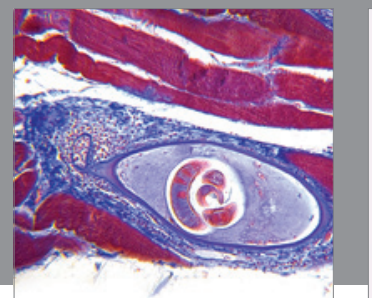

Gastroenterology

Research and Practice
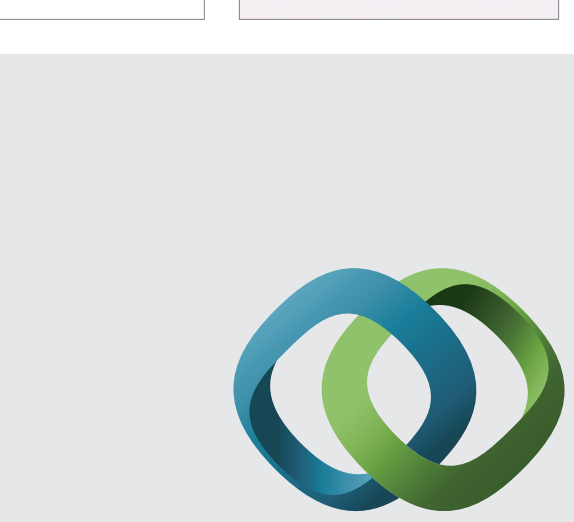

\section{Hindawi}

Submit your manuscripts at

http://www.hindawi.com
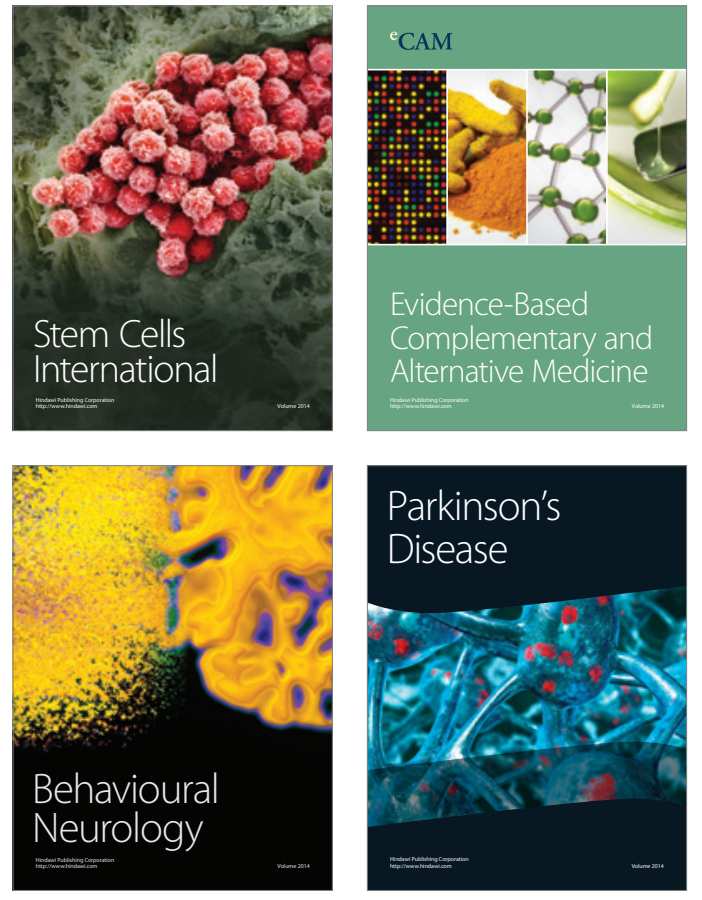
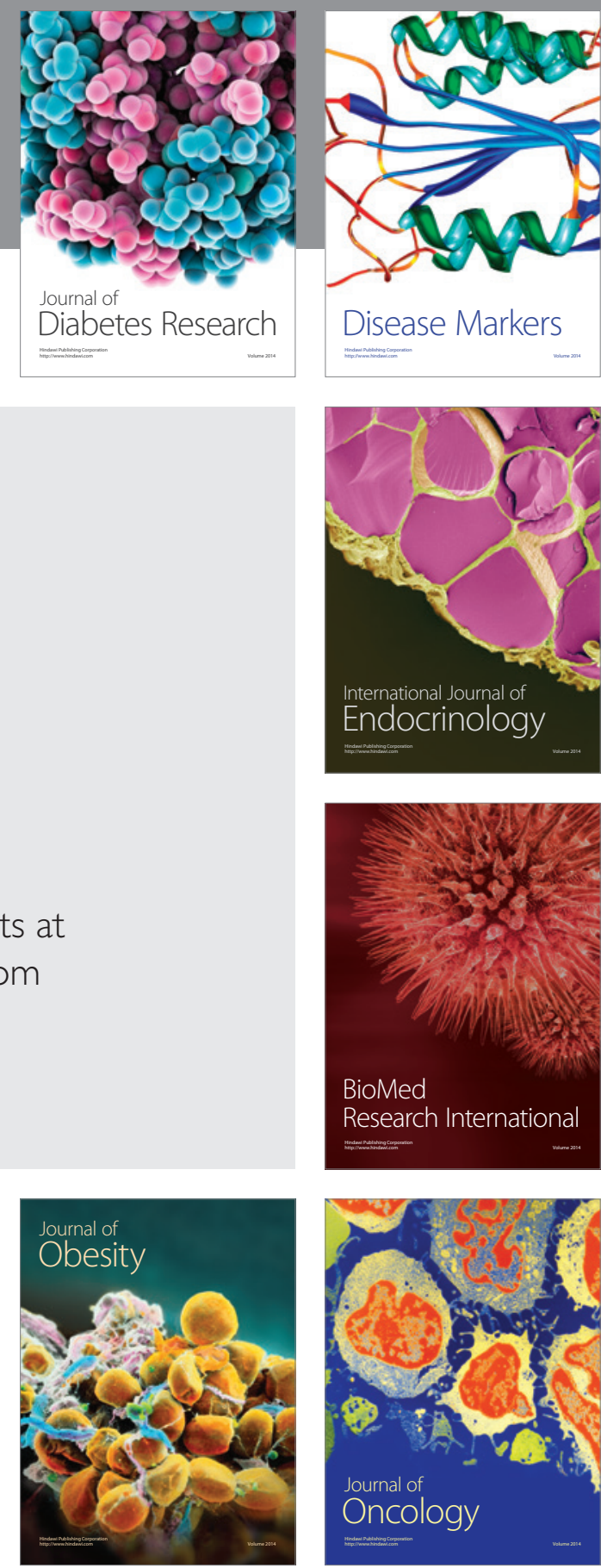

Disease Markers
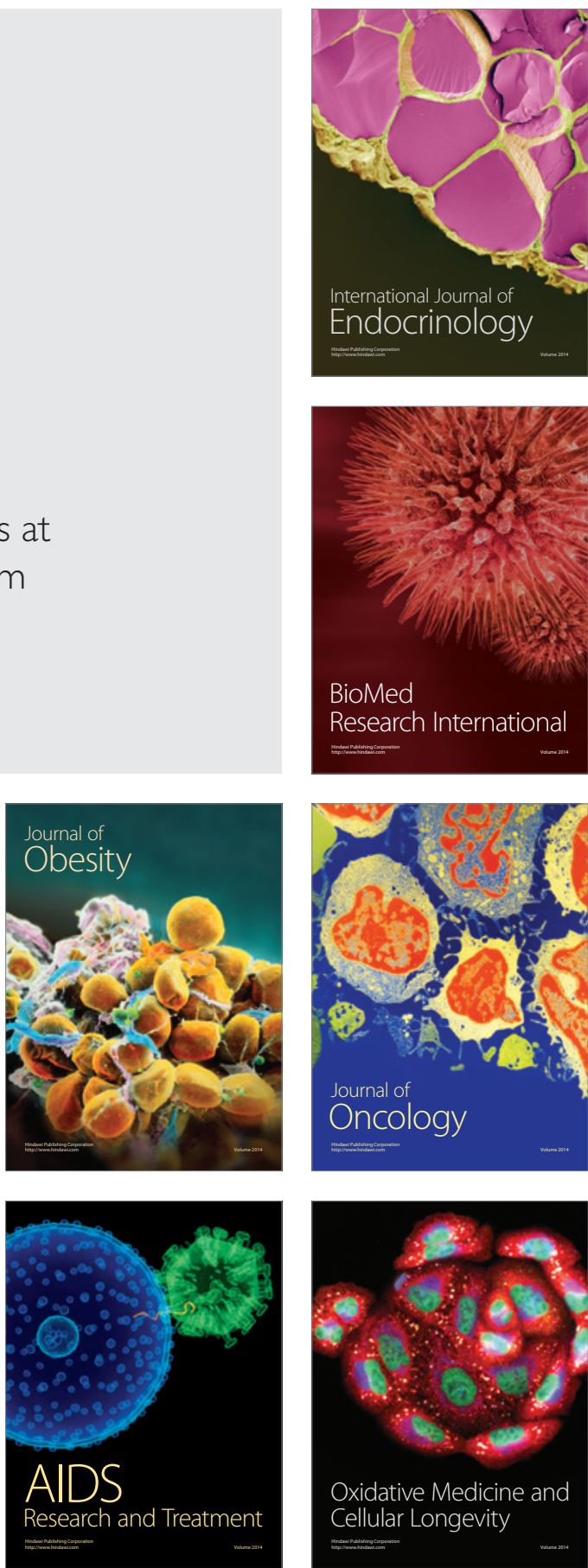